\title{
Improved patient-reported outcomes in patients with psoriatic arthritis treated with abatacept: results from a phase 3 trial
}

Vibeke Strand ${ }^{1}$, Evo Alemao ${ }^{2 *}$, Thomas Lehman², Alyssa Johnsen², Subhashis Banerjee ${ }^{2}$, Harris A. Ahmad ${ }^{2}$ and Philip J. Mease ${ }^{3}$

\begin{abstract}
Background: To explore the effect of abatacept treatment on patient-reported outcomes (PROs) in psoriatic arthritis (PsA).

Methods: Patients with PsA were randomised (1:1) to subcutaneous abatacept $125 \mathrm{mg}$ weekly/placebo for 24 weeks with early escape (EE) to open-label abatacept (week 16). Adjusted mean changes from baseline to weeks 16 (all patients) and 24 (non-EE responders) in Health Assessment Questionnaire-Disability Index (HAQ-DI), Short Form-36 (SF-36; physical and mental component summary and domains), Dermatology Life Quality Index and Functional Assessment of Chronic Illness Therapy-Fatigue (FACIT-F) were evaluated. Subpopulations were analysed by baseline C-reactive protein (CRP) level (> vs $\leq$ upper limit of normal [ULN]) and prior tumour necrosis factor inhibitor (TNFi) exposure. Proportions of patients reporting improvements $\geq$ minimal clinically important differences (MCIDs) and $\geq$ normative values (NVs) in HAQ-DI, SF-36 and FACIT-F (week 16 before EE) were analysed.

Results: In total population, numerically higher improvements in most PROs were reported with abatacept $(n=213)$ versus placebo $(n=211)$ at both time points $(P>0.05)$. Higher proportions of abatacept versus placebo patients reported PRO improvements $\geq M C I D$ and $\geq N V$ at week 16 . At week 16, all PRO improvements were numerically greater $(P>0.05)$ in patients with baseline CRP $>U L N$ versus CRP $\leq U L N$ (all significant [95\% confidence interval] for abatacept vs placebo); improvements in SF-36 component summaries and FACIT-F were greater in TNFi-naïve versus TNFi-exposed patients (abatacept $>$ placebo). Week 24 subgroup data were difficult to interpret due to low patient numbers.
\end{abstract}

Conclusions: Abatacept treatment improved PROs in patients with PSA versus placebo, with better results in elevated baseline CRP and TNFi-naïve subpopulations.

Trial registration: ClinicalTrials.gov number, NCT01860976 (funded by Bristol-Myers Squibb); date of registration: 23 May 2013.

Keywords: DMARDs (biologic), Outcomes research, Patient perspective, Psoriatic arthritis

\footnotetext{
* Correspondence: evo.alemao@bms.com

${ }^{2}$ Bristol-Myers Squibb, Princeton, NJ, USA

Full list of author information is available at the end of the article
}

(c) The Author(s). 2018 Open Access This article is distributed under the terms of the Creative Commons Attribution 4.0 International License (http://creativecommons.org/licenses/by/4.0/), which permits unrestricted use, distribution, and reproduction in any medium, provided you give appropriate credit to the original author(s) and the source, provide a link to the Creative Commons license, and indicate if changes were made. The Creative Commons Public Domain Dedication waiver (http://creativecommons.org/publicdomain/zero/1.0/) applies to the data made available in this article, unless otherwise stated. 


\section{Background}

Psoriatic arthritis (PsA) is a chronic inflammatory autoimmune disease with a range of clinical manifestations affecting skin and musculoskeletal systems [1]. Healthrelated quality of life (HRQoL) can vary greatly according to a patient's specific symptoms; hence, assessing treatment effects using patient-reported outcomes (PROs) is particularly important in PsA [2-6]. Several PRO instruments have been validated in PsA, including the Health Assessment Questionnaire-Disability Index (HAQ-DI) $[4,7]$ and Short Form-36 (SF-36) [5, 6].

Abatacept, a selective T-cell co-stimulation modulator [8], has a distinct mechanism of action upstream of currently available agents, and is approved for treatment of rheumatoid arthritis and juvenile idiopathic arthritis, and recently for active PsA in adults [9]. In the phase 3 Active pSoriaTic aRthritis rAndomizEd triAl (ASTRAEA, NCT01860976), subcutaneous (SC) abatacept $125 \mathrm{mg}$ weekly significantly increased the proportion of patients achieving $\geq 20 \%$ improvement in the American College of Rheumatology criteria (ACR20) compared with placebo at week 24 (primary endpoint: $39.4 \%$ vs $22.3 \% ; P<0.001$ ) and was well tolerated in patients with active PsA [10]. A numerically higher proportion of patients with HAQ-DI responses (reductions from baseline $\geq 0.35$ ) was evident with abatacept versus placebo $(P>0.05)$. Abatacept treatment also reduced progression of structural damage with an overall beneficial effect on musculoskeletal symptoms. However, due to the hierarchical testing procedure employed, it was not possible to attribute significance to endpoints ranked below HAQDI responses in the hierarchical testing [10].

The effect of factors associated with poor prognosis and treatment resistance, such as elevated C-reactive protein (CRP) levels and prior exposure to tumour necrosis factor inhibitors (TNFi) [11], was also evaluated in ASTRAEA. Higher ACR20 responses were observed with abatacept versus placebo in both TNFi-naive and TNFi-exposed subpopulations at week 24 , with the largest treatment differences seen in TNFi-naïve patients [10]. Moreover, patients with baseline CRP $\geq$ upper limits of normal (ULN) had the highest ACR20 responses at week 24 with abatacept versus placebo [10].

The goal of the analyses reported here was to examine the impact of abatacept versus placebo treatment on PROs in ASTRAEA for the overall population and in subgroups by baseline CRP levels and previous TNFi exposure.

\section{Methods}

\section{Study design and treatment}

The design, eligibility criteria, and main efficacy and safety endpoints of this phase 3, randomised, double-blind, placebo-controlled, multicentre trial have been reported in detail previously [10]. Patients were randomised (1:1) to receive SC abatacept $125 \mathrm{mg}$ weekly or placebo for 24 weeks, after which all patients were transitioned to receive open-label SC abatacept weekly for 28 weeks (total study period of 52 weeks). Patients without $\geq 20 \%$ improvement in tender and swollen joint counts at week 16 were switched to open-label abatacept for 28 weeks (early escape [EE], total study period of 44 weeks). Key eligibility criteria included age $\geq 18$ years, PsA per the Classification Criteria for PsA (CASPAR) [12], active arthritis (defined as $\geq 3$ tender and $\geq 3$ swollen joints), active plaque psoriasis with $\geq 1$ qualifying target lesion $\geq 2 \mathrm{~cm}$ in diameter and inadequate response or intolerance to $\geq 1$ non-biologic disease-modifying antirheumatic drug (DMARD). Both TNFi-naïve and TNFiexposed patients were included.

\section{Patient-reported outcomes}

HAQ-DI [4, 7], SF-36 physical component summary (PCS), mental component summary (MCS) and individual domain scores [5, 6], Functional Assessment of Chronic Illness Therapy-Fatigue scale (FACIT-F) [3] and Dermatology Life Quality Index (DLQI) [2] scores were assessed at weeks 16 and 24 in the overall population (prespecified) and in patient subpopulations (post hoc) by baseline CRP (> or $\leq \mathrm{ULN}$, defined as $3 \mathrm{mg} / \mathrm{L}$ ) and prior TNFi use. The hierarchical order of the secondary and exploratory PRO endpoints [10] was predefined as: proportions of patients reporting HAQ-DI responses $\geq$ minimal clinically important differences (MCIDs) and mean changes from baseline in SF-36 PCS and MCS scores (summary and domain scores).

Here, in the overall population, the proportions of patients reporting improvements from baseline in HAQ-DI, SF-36 (summary and domain) and FACIT-F scores $\geq$ MCID (expressed as a value established for each instrument, and defined as the smallest change in score perceived by a patient to be clinically important) [13] and $\geq$ normative values (defined based on age/gender-matched population) were analysed (post hoc) at week 16 prior to confounding due to EE to open-label abatacept treatment. Defined MCIDs were: HAQ-DI $\geq-0.35$ [14], SF-36 PCS $\geq 2.5$ [13, 15-17], SF-36 MCS $\geq 2.5[13,15,17]$, SF-36 domains $\geq 5.0[13,15,17]$, and FACIT-F $\geq-4.0$ [3]. Normative values were: HAQ-DI $<0.5$ [7, 18, 19], SF-36 $\mathrm{PCS} \geq 50[17,20], \mathrm{SF}-36 \mathrm{MCS} \geq 50[20]$ and FACIT-F $\geq$ 40.1 [21].

\section{Statistical analyses}

All efficacy analyses included all randomised patients who received at least one dose of study medication (intent-totreat population). Week 16, prior to EE, was the last time point at which all patients were analysed. For week 24 analyses, EE patient data were set to missing. As previously reported, the effect of abatacept on the first key 
secondary endpoint in the statistical hierarchy (HAQ-DI responses) did not reach significance; therefore, only nominal $P$ values were generated for subsequent outcomes, which were ranked lower in the hierarchy. The significance of the treatment effect cannot be definitively attributed for these outcomes as they were not adjusted for multiplicity (however, 95\% confidence intervals [CIs] were not overlapping) [10]. Nonetheless, these lower-ranking outcomes still provide a measure of clinical meaningfulness. Adjusted mean changes from baseline in PROs including SF-36 domain scores were evaluated, and corresponding adjusted mean differences $(95 \% \mathrm{CI})$ between the abatacept and placebo groups were calculated using a longitudinal repeated measures model. This model included the fixed categorical effects of treatment, day, prior TNFi use, methotrexate (MTX) use, body surface area (BSA), day-by-treatment interaction, prior TNFi-use-by-day interaction, MTX-useby-day interaction, BSA-use-by-day interaction and the continuous fixed covariate of baseline score and baseline score-by-day interaction. The estimate of difference (95\% CI) between abatacept and placebo groups for MCID and normative values was calculated using a two-sided Cochran-Mantel-Haenszel chi-square test adjusted for stratification criteria.

\section{Patient consent and ethics approval}

All patients or their legal representatives gave written, informed consent prior to study entry. The study was conducted in accordance with the Declaration of Helsinki, International Conference on Harmonisation Guidelines for Good Clinical Practice and local regulations. Schulman Associates Institutional Review Board or Independent Ethics Committees approved the protocol, consent form and any other written information provided to patients or their legal representatives.

\section{Results \\ Patients}

Of 424 patients randomised, 213 received abatacept and 211 placebo; 76 (35.7\%) and 89 (42.2\%), respectively, met criteria for EE [10]. Baseline demographic and disease characteristics were similar between treatment groups and were reported in detail previously [10].

\section{Overall population analysis \\ Changes from baseline at weeks 16 and 24}

In the total population, greater improvements from baseline in most PROs were reported with abatacept versus placebo at both week 16, which comprised all patients,

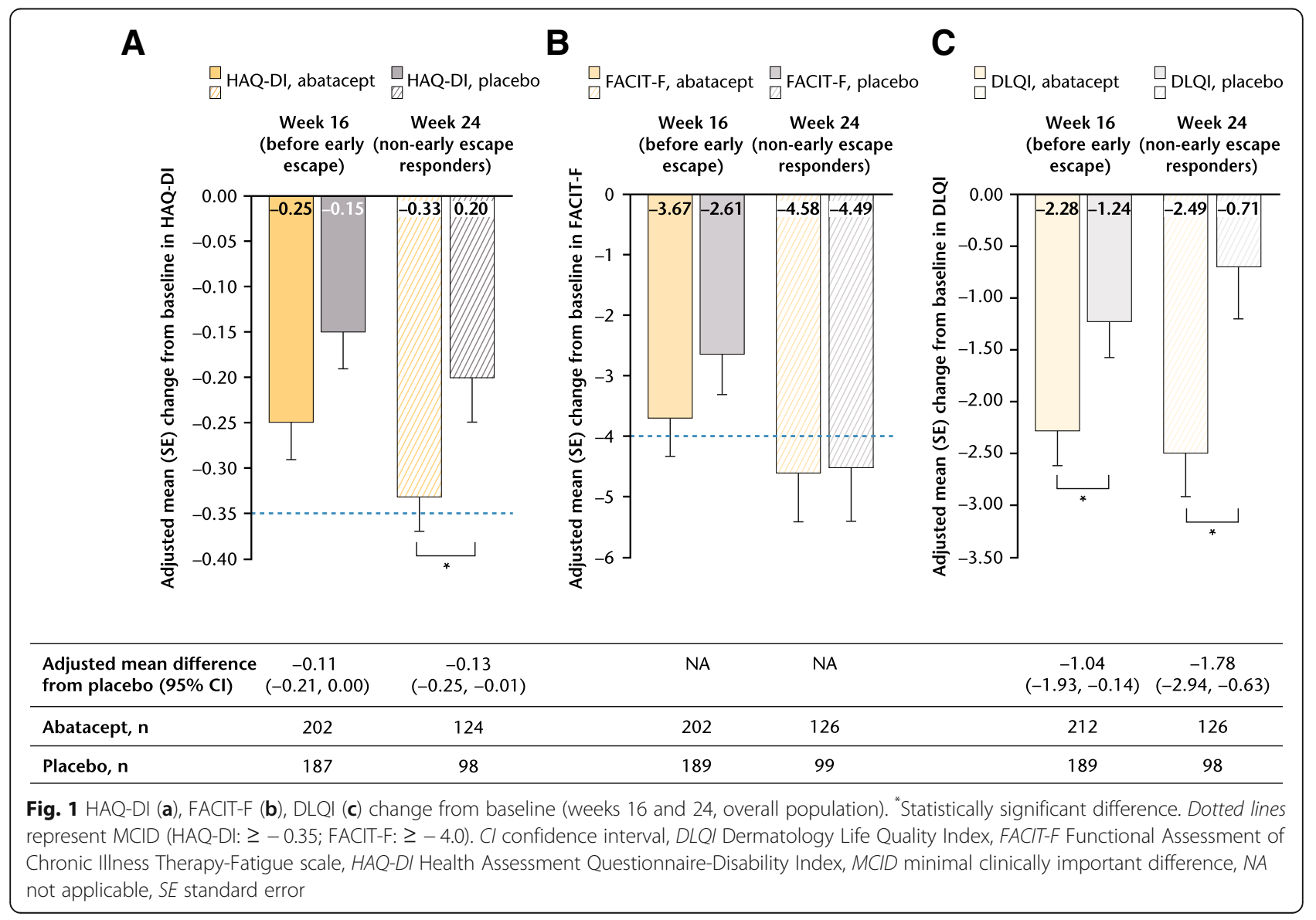


and week 24, which included only patients showing a response to either treatment (response defined as 20\% improvement in tender and swollen joint counts; Figs. 1, 2 and 3a). Statistically significant (95\% CI of difference vs placebo not crossing 0 ) improvements from baseline with abatacept versus placebo were reported in HAQ-DI scores in the week 24 responder group (Fig. 1a), in SF-36 PCS (Fig. 2), SF-36 physical functioning (PF), bodily pain (BP) and vitality (VT) domains (adjusted mean difference [95\% CI], respectively: 4.44 [0.39 to 8.49], 5.36 [1.40 to 9.33] and 4.07 [0.67 to 7.47]), and in DLQI (Fig. 1c) scores at weeks 16 and 24 .

Changes from baseline in SF-36 MCS scores were not statistically significant, but were numerically greater with abatacept versus placebo at week 16 (adjusted mean change from baseline [standard error (SE)]: 2.42 [0.70] vs 1.15 [0.73], adjusted mean difference [95\% CI]: 1.28 [ -0.58 to 3.13]; $P>0.05$ ), but were not meaningfully different for the responder-only analysis at week 24 (adjusted change from baseline [SE]: 2.56 [0.83] vs 2.62 [0.92], adjusted mean difference [ $95 \% \mathrm{CI}]:-0.06$ [ -2.32 to 2.20$]$ ). All SF-36 domains showed nonsignificant trends towards greater improvements from baseline with abatacept than placebo at week 16; improvements from baseline in all domains increased in both abatacept and placebo groups among responders at week 24. (Fig. 3a; see Additional file 1: Table S1).

\section{Minimal clinically important differences and normative values}

A statistically significant benefit at week 16 with abatacept versus placebo was evident in SF-36 PCS and MCS scores, and PF, BP and role-emotional (RE) domains (Fig. 4a; see Additional file 2: Table S2). The proportions of patients reporting scores $\geq$ normative values at week 16 were significantly greater (estimate of difference $[95 \% \mathrm{CI}]$ ) with abatacept versus placebo in FACIT-F (10.4 [0.4 to 20.3]) and SF-36 RE domain (10.3 [3.4 to 17.1]) scores.

A numerically greater proportion of patients reported improvements $\geq$ MCID with abatacept versus placebo at week 16 in HAQ-DI scores, but the difference did not reach statistical significance (Fig. 4a). At week 16, the proportion of patients reporting improvements $\geq$ MCID in FACIT-F scores (Fig. 4a) and SF-36 role-physical (RP), general health $(\mathrm{GH}), \mathrm{VT}$, social function and mental health $(\mathrm{MH})$ domain scores (see Additional file 2: Table S2) were numerically higher with abatacept versus placebo. In the abatacept treatment group, changes from baseline exceeded MCID in six of eight SF-36 domains, the exceptions being $\mathrm{GH}$ and $\mathrm{MH}$; whereas in the placebo group, mean changes exceeded MCID in the RP and BP domains only.

The proportions of patients who reported scores $\geq$ normative values at week 16 , although not statistically significant, were numerically higher with abatacept than

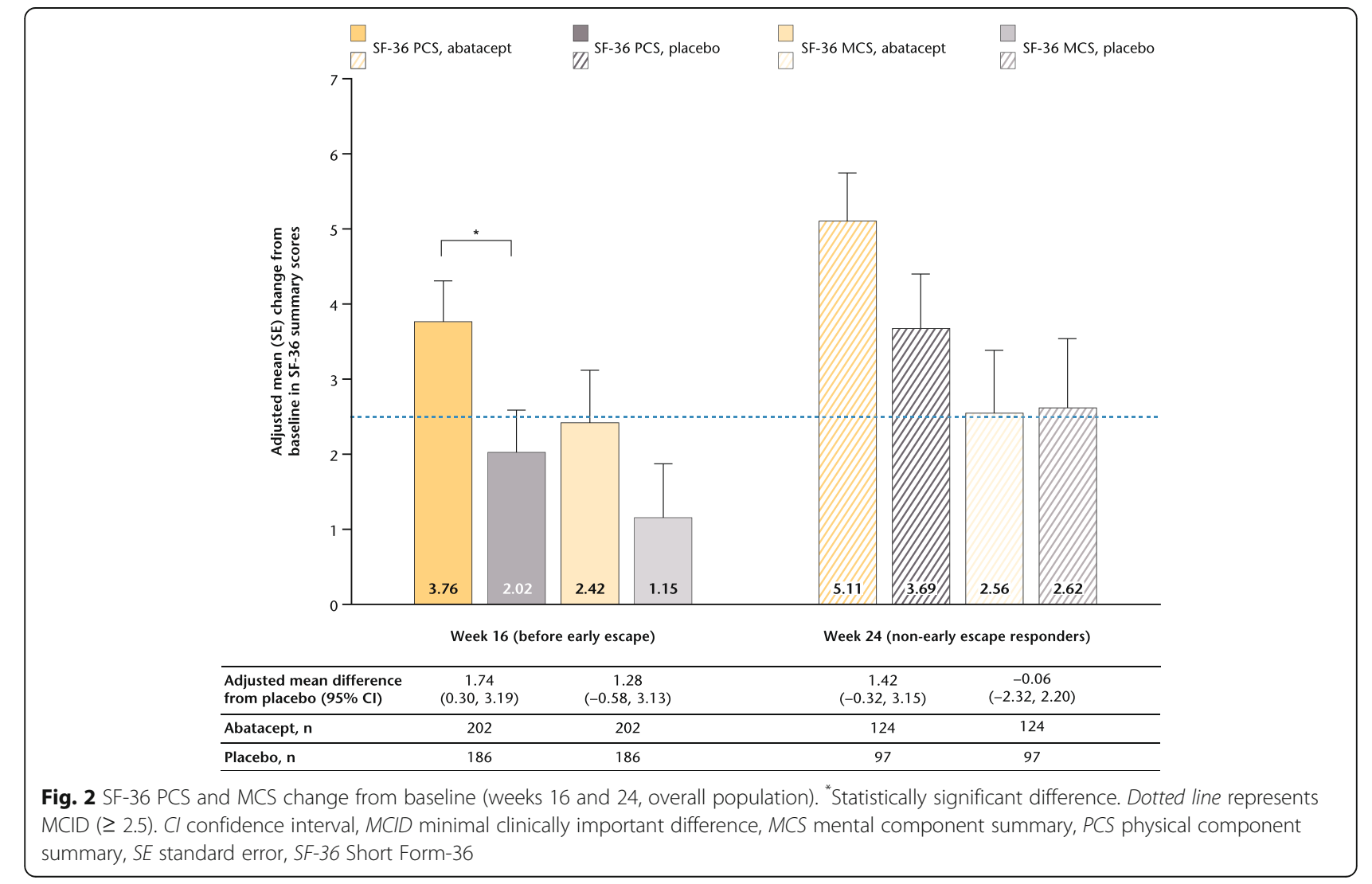



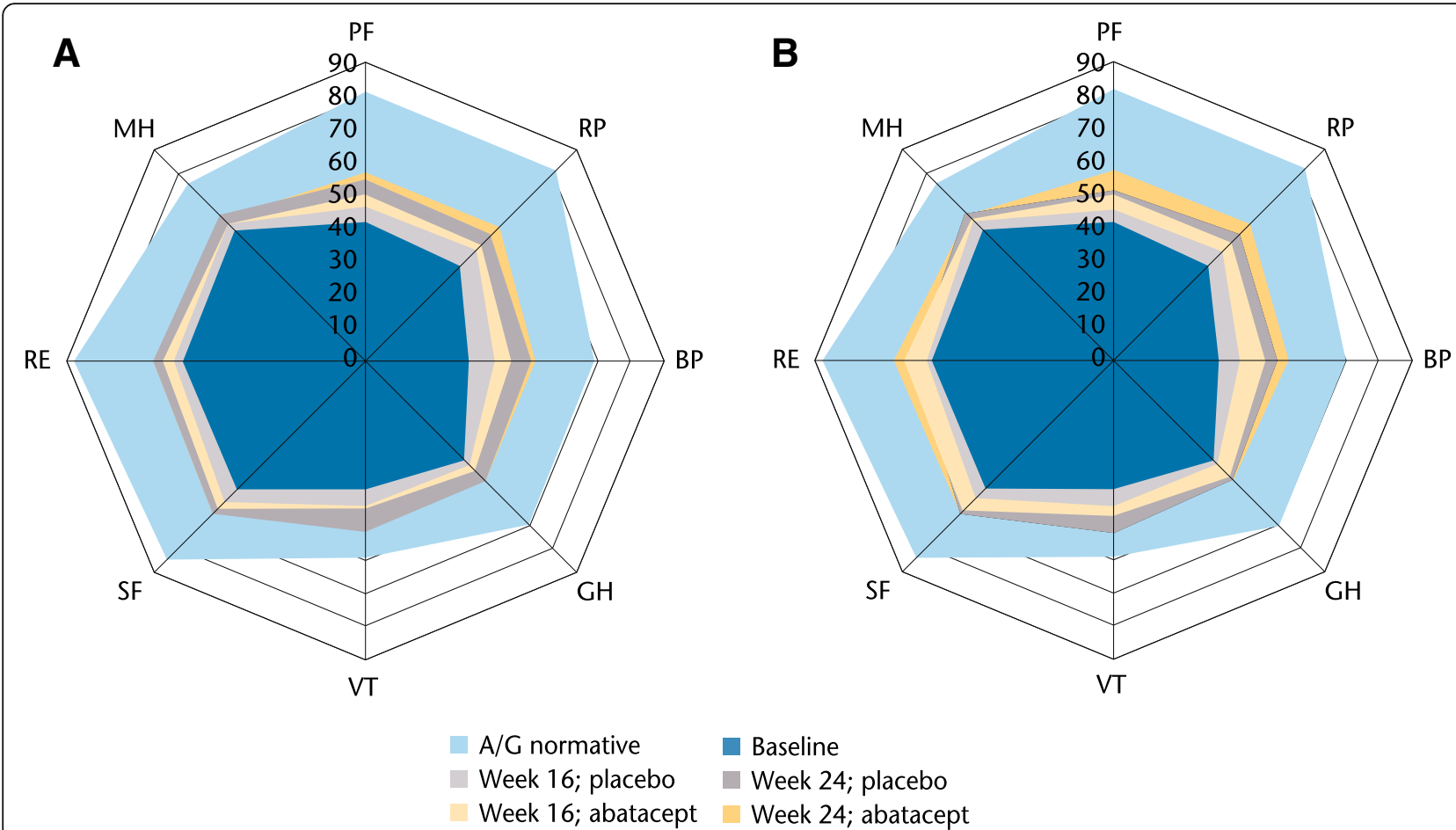

Fig. 3 Abatacept/placebo SF-36 domain scores (baseline, weeks 16, 24) versus normative population (a, overall; $\mathbf{b}$, CRP > ULN). Normative values for SF-36 individual domains were defined based on matching the age/gender distribution of this protocol population to US 1999 norms in patients without chronic disease or arthritis [20,34]: PF and RP 81.9, BP 69.7, GH 70.4, VT 59.3, SF 84.4, RE 87.8, MH 75.6. A/G age/gender, BP bodily pain, CRP C-reactive protein, GH general health, MH mental health, PF physical function, RE role-emotional, RP role-physical, SF social function, SF-36 Short-Form 36, ULN upper limit of normal, VT vitality

placebo in HAQ-DI, SF-36 PCS and MCS, and FACIT-F (Fig. 4b) scores and all SF-36 domains (see Additional file 3: Table S3) $(P>0.05)$.

\section{Subpopulation analyses}

\section{Changes from baseline at weeks 16 and 24}

Across all PROs, improvements from baseline to week 16, although not statistically significant, were numerically greater in patients with baseline CRP $>$ ULN versus those with $\mathrm{CRP} \leq \mathrm{ULN}$ in both abatacept and placebo groups $(P>0.05$; Table 1$)$. In the CRP $>$ ULN subpopulation, improvements with abatacept versus placebo were significantly greater in HAQ-DI, SF-36 PCS, MCS, FACIT-F and DLQI scores (Table 1). Across all SF-36 domains, with the exception of $\mathrm{MH}$, statistically significantly greater improvements were reported at week 16 with abatacept versus placebo in patients with baseline CRP > ULN (Fig. 3b and Fig. 5). Statistically significant improvements (adjusted mean difference [95\% CI]) in DLQI $(-2.32[-3.80$ to -0.83 ]; Table 1$)$ and SF-36 PF (8.57 [2.15 to 14.99]) and BP (6.62 [0.15 to 13.09]) (Fig. 5b) domain scores were reported in the baseline CRP > ULN subpopulation with abatacept versus placebo at week 24; however, data should be interpreted with caution due to low patient numbers. In the CRP $\leq$ ULN subpopulation, no significant improvements with abatacept versus placebo were evident at week 16 (Table 1).

A statistically significant benefit for abatacept versus placebo was reported by TNFi-naïve patients at week 16 in SF-36 MCS (Table 1) scores. Among abatacepttreated TNFi-naïve patients at baseline, numerically, although not statistically significant, greater improvements in SF-36 PCS, MCS and FACIT-F scores at week 16 were reported versus TNFi-exposed patients $(P>0.05$; Table 1$)$. In the TNFi-naïve abatacept-treated subpopulation, adjusted mean changes from baseline at week 16 exceeded MCID in SF-36 PCS, MCS and FACIT- F scores (Table 1), and seven of eight SF-36 domains with exception of $\mathrm{MH}$ (data not shown). In TNFi-exposed abatacept-treated patients, improvements exceeded MCID in SF-36 PCS scores (Table 1).

\section{Discussion}

These analyses demonstrated that abatacept treatment generally improved PROs in patients with active PsA in the phase 3 ASTRAEA trial, particularly in those who were TNFi-naïve and/or with elevated CRP at baseline. In the overall population at week 16 , prior to $\mathrm{EE}$, 


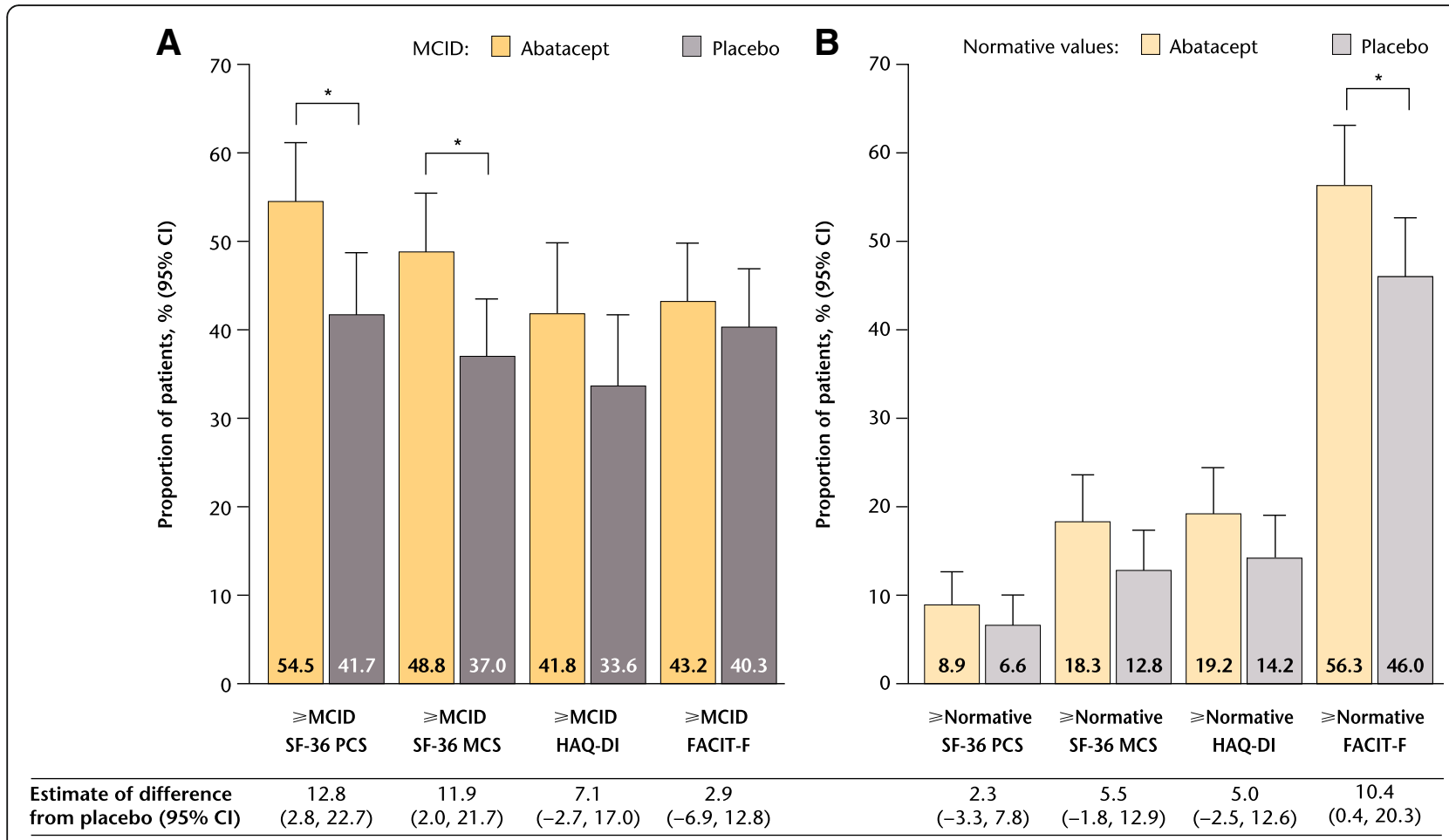

Fig. 4 Rates of PRO improvements $\geq$ MCID (a) or $\geq$ normative values (b) at week 16 (overall population). "Statistically significant difference. MCID values: HAQ-DI $\geq-0.35$, SF-36 PCS $\geq 2.5$, SF-36 MCS $\geq 2.5$, FACIT-F $\geq-4.0$ and SF-36 domains $\geq 5.0$. Normative values: HAQ-DI $\geq 0.5$, SF-36 PCS $\geq 50$, SF-36 MCS $\geq 50$ and FACIT-F $\geq 4$ 40.1. Cl confidence interval, FACIT-F Functional Assessment of Chronic Illness Therapy-Fatigue scale, HAQ-D/ Health Assessment Questionnaire-Disability Index, MCID minimal clinically important difference, MCS mental component summary, PCS physical component summary, PRO patient-reported outcome, SF-36 Short Form-36

abatacept administration was associated with improved PROs compared with placebo; significant improvements with abatacept versus placebo were reported in SF-36 PCS, PF, BP and VT domain scores as well as DLQI, reflecting those areas of HRQoL most impacted by PsA. At week 24 in the non-EE responder analysis, a potential benefit of abatacept treatment was evident compared with placebo, with significantly greater improvements reported in physical function (by HAQ-DI) and dermatological manifestations (by DLQI). The proportion of patients with clinically meaningful HAQ-DI responses (reductions from baseline score $\geq 0.35$ ) at week 24 was numerically higher with abatacept versus placebo: $31.0 \%$ versus $23.7 \%$; however, as this did not reach statistical significance, it was not possible to definitively attribute significance to lower-ranking secondary endpoints in the hierarchical testing (nominal $P$ values only were generated; 95\% CIs were not overlapping) [10]. Notably, significant improvements in DLQI, the only PRO investigated here that directly measures the skin domain in PsA, were reported by those patients with a background of an overall modest skin response (by Psoriatic Area and Severity Index) in ASTRAEA at week 24 [10]. Nevertheless, as the week 24 analysis included only non-EE responders, the placebo arm comprised patients who reported responses to placebo. Therefore, it may be expected that differences between treatment groups would be less obvious at week 24 than week 16. In addition, the number of patients analysed at this time point was lower than at week 16.

Comparisons of the proportion of patients reporting improvements $\geq$ MCID is considered a clinically meaningful estimate of therapy effects [22]. Overall, the proportion of abatacept-treated patients reporting improvements $\geq$ MCID in PROs exceeded the proportion of placebo-treated patients: at week $16,41.8-58.2 \%$ of abatacept-treated patients across different PROs reported clinically meaningful improvements in HAQ-DI, SF-36 PCS and MCS, individual SF-36 domains and FACIT-F scores compared with $33.6-47.9 \%$ of those treated with placebo.

In addition to the overall population analysis, PROs were analysed in subpopulations of patients by baseline CRP, as elevated CRP is an identified poor prognostic factor [11]. There was a non-statistically significant trend towards improved PROs in patients with elevated baseline CRP regardless of treatment arm at week 16. However, among patients with elevated CRP, those receiving abatacept reported greater improvements compared with placebo. Similarly, in the main ASTRAEA study, the highest 


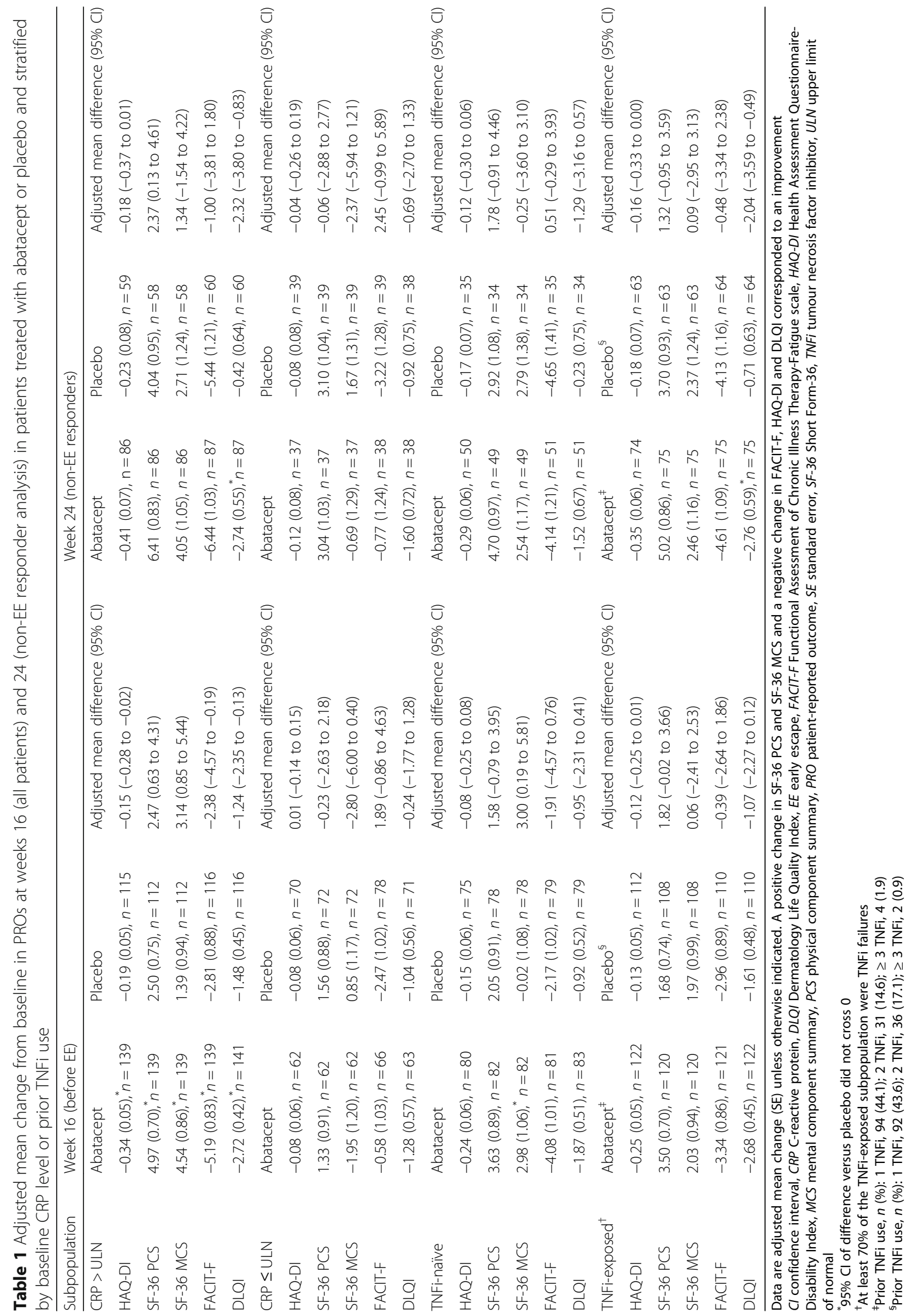




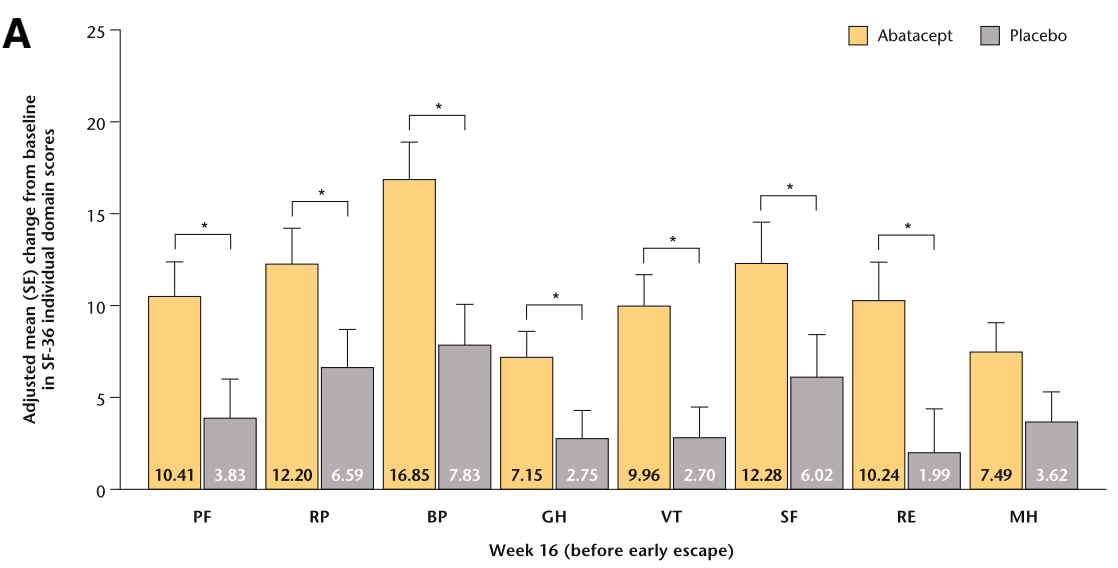

\begin{tabular}{lcccccccc}
\hline $\begin{array}{l}\text { Adjusted mean difference } \\
\text { from placebo }(95 \% \mathrm{Cl})\end{array}$ & 6.58 & 5.61 & 9.02 & 4.40 & 7.26 & 6.26 & 8.25 & 3.87 \\
& $(1.45,11.70)$ & $(0.57,10.65)$ & $(3.91,14.14)$ & $(0.79,8.02)$ & $(2.90,11.63)$ & $(0.59,11.93)$ & $(2.60,13.89)$ & $(-0.16,7.90)$ \\
\hline Abatacept, $\mathbf{n}$ & 140 & 140 & 139 & 140 & 140 & 140 & 140 & 140 \\
\hline Placebo, $\mathbf{n}$ & 113 & 113 & 113 & 113 & 112 & 113 & 113 & 112 \\
\hline
\end{tabular}

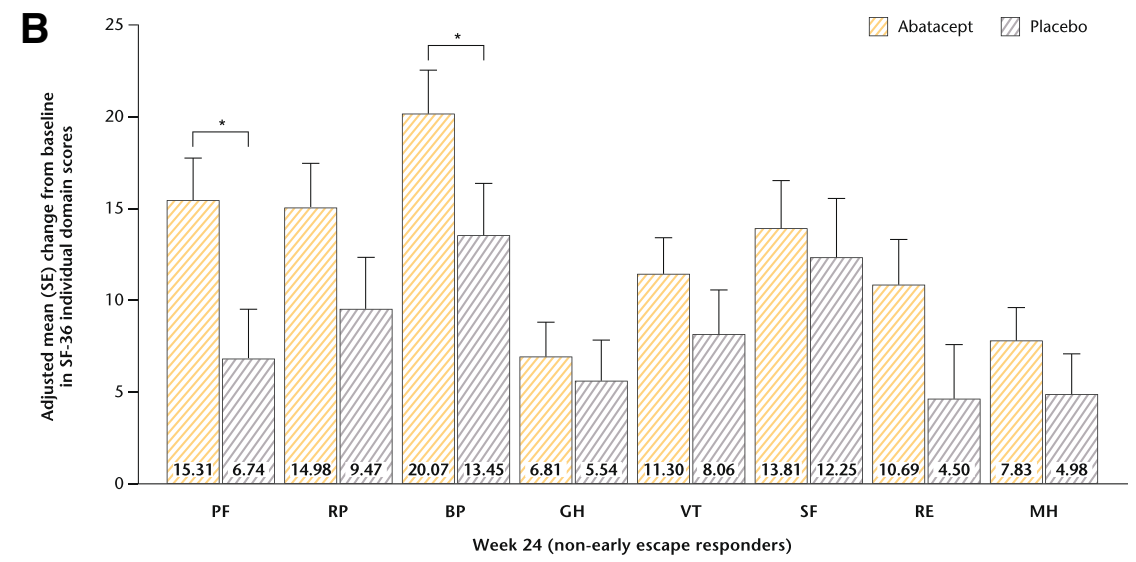

\begin{tabular}{lcccccccc}
\hline $\begin{array}{l}\text { Adjusted mean difference } \\
\text { from placebo }(95 \% \mathrm{Cl})\end{array}$ & 8.57 & 5.51 & 6.62 & 1.27 & 3.24 & 1.56 & 6.19 & 2.85 \\
& $(2.15,14.99)$ & $(-1.04,12.06)$ & $(0.15,13.09)$ & $(-3.99,6.53)$ & $(-2.40,8.89)$ & $(-5.76,8.88)$ & $(-0.79,13.18)$ & $(-2.25,7.95)$ \\
\hline Abatacept, $\mathbf{n}$ & 87 & 87 & 87 & 87 & 86 & 87 & 87 & 86 \\
\hline Placebo, $\mathbf{n}$ & 58 & 58 & 58 & 58 & 58 & 58 & 58 & 58 \\
\hline
\end{tabular}

Fig. 5 SF-36 domain score changes from baseline for CRP > ULN population: weeks 16 (a) and 24 (b). . ${ }^{*}$ tatistically significant difference. BP bodily pain, Cl confidence interval, CRP C-reactive protein, GH general health, MH mental health, PF physical function, RE role-emotional, $R P$ role-physical, SE standard error, SF social function, SF-36 Short Form-36, VT vitality

ACR20 responses with abatacept versus placebo were seen in patients with CRP > ULN at baseline [10], suggesting that these patients may be particularly responsive to abatacept. Our results suggest that baseline CRP should be taken into consideration when evaluating the clinical efficacy of different treatments. PROs were also analysed in subpopulations by previous exposure to TNFi treatment. At week 16, improvements were greater with abatacept than with placebo in both TNFi-naïve and TNFi-exposed subpopulations. However, in abatacept-treated patients, reported improvements in PROs were generally larger in the TNFi-naïve versus TNFi-exposed subpopulations. Indeed, greater efficacy would be expected in TNFi-naïve than in TNFi-exposed patients [23]. These findings are in line with clinical outcomes observed with abatacept in this trial, which were generally better in patients with elevated CRP at baseline and TNFi-naïve patients [10]. The PRO data reported here support previous results that abatacept may be particularly effective in certain subpopulations of patients.

The effects of other DMARDs, including TNFi agents, on PROs in patients with active PsA have been investigated previously, with most studies assessing effects over 24 or 48 weeks. Statistically and clinically meaningful improvements in SF-36 PCS and MCS and all individual domain scores from baseline to week 24 have been reported with etanercept [24]; clinically meaningful improvements in PROs including HAQ-DI and SF-36 PCS scores have also 
been reported over 48 weeks of treatment [25]. Similarly, adalimumab has been shown to improve HRQoL, based on SF-36 PCS, HAQ-DI, FACIT-F and DLQI scores, after 48 weeks of treatment [26]. The effects of the newer interleukin inhibitors on PROs have also been studied. Ustekinumab, an anti-interleukin-12 and -23 agent, improved physical function (by SF-36 PCS and HAQ-DI) and dermatological manifestations (by DLQI) at week 24 [27, 28]. Beneficial effects on PROs have also been reported after 24 weeks with the anti-interleukin-17A agent secukinumab $[29,30]$. Furthermore, apremilast, a phosphodiesterase 4 inhibitor, was shown to significantly improve HAQ-DI scores by week 16 compared with placebo in a 24 -week trial in which $<10 \%$ of patients had previously failed a biologic therapy [31]. In the current study, improvements in PROs achieved with abatacept appeared less marked than that reported with other biologic DMARDs (bDMARDs) in earlier studies; however, differences in trial design and patient populations preclude comparisons of efficacy between abatacept and other bDMARDs based on currently available evidence.

The therapeutic options for PsA have greatly increased over the past 10 years and, as more new treatments are introduced, assessing responses to therapy including PROs will become increasingly important, aiding treatment choices. A recent literature review provided an evidencebased overview of 44 instruments per core PsA outcome domain to ascertain applicability and best instrument for each domain of the many available PROs [32]. However, further research is warranted to develop and validate specific PRO measures that better capture the impact of all PsA symptoms [33]. In the meantime, using a combination of instruments and/or the best available instrument per domain, as in this trial, provides a more complete picture [33].

A number of study limitations should be considered. First, subpopulation comparisons and ascertainment of scores $\geq$ MCID and $\geq$ normative values were post hoc in nature. Second, owing to the particular trial design, a high proportion of patients were subject to EE at week 16; as such, week 24 analyses included a limited number of patients who were still receiving blinded treatment in either arm of the trial. Only nominal $P$ values were provided for endpoints that ranked lower in the statistical hierarchy than the first secondary endpoint, which did not reach statistical significance at the $5 \%$ level. For other endpoints, only $95 \%$ CIs of differences between abatacept and placebo arms were generated, without associated $P$ values. In addition, due to the low patient numbers, the reported data for subpopulations were difficult to interpret, particularly at week 24. Finally, certain PROs may improve less rapidly over time and thus the week 16 time point may have not allowed maximal effects of abatacept treatment to be observed. In addition, although some statistically significant improvements were noted with abatacept, these may not necessarily be clinically important.

\section{Conclusions}

In conclusion, abatacept treatment improved PROs at week 16 in patients with active PsA, with evidence of some effects sustained at week 24. Furthermore, PRO improvements were greater in TNFi-naïve patients and those with elevated CRP. These results demonstrate that clinical improvements in PsA signs and symptoms previously reported with abatacept treatment [10] also result in clinically meaningful improvements in PROs.

\section{Additional files}

Additional file 1: Table S1. Adjusted mean change from baseline in SF36 individual domains at weeks 16 (all patients) and 24 (non-EE responder analysis) in patients treated with abatacept or placebo (overall population). (DOCX $36 \mathrm{~kb}$ )

Additional file 2: Table S2. Proportion of patients $(95 \% \mathrm{Cl})$ treated with abatacept or placebo reporting improvements $\geq$ MCID in SF-36 individual domains at week 16 (all patients) in the overall population. (DOCX $14 \mathrm{~kb}$ )

Additional file 3: Table S3. Proportion of patients $(95 \% \mathrm{Cl})$ treated with abatacept or placebo reporting improvements $\geq$ normative values in SF-36 individual domains at week 16 (all patients) in the overall population. (DOCX $14 \mathrm{~kb}$ )

\section{Abbreviations}

ACR20: American College of Rheumatology criteria; ASTRAEA: Active pSoriaTic aRthritis rAndomizEd triAl; bDMARDS: Biologic disease-modifying anti-rheumatic drugs; BP: Bodily pain; BSA: Body surface area; CASPAR: Classification Criteria for Psoriatic Arthritis; Cl: Confidence interval; CRP: C-reactive protein; DLQI: Dermatology Life Quality Index; DMARD: Disease-modifying antirheumatic drug; EE: Early escape; FACIT-F: Functional Assessment of Chronic Illness Therapy-Fatigue; GH: General health; HAQ-DI: Health Assessment Questionnaire-Disability Index; HRQoL: Health-related quality of life; MCID: Minimal clinically important difference; MCS: Mental component summary; MH: Mental health; MTX: Methotrexate; NV: Normative values; PCS: Physical component summary; PF: Physical functioning; PRO: Patient-reported outcome; PsA: Psoriatic arthritis; RE: Role-emotional; RP: Role-physical; SC: Subcutaneous; SE: Standard error; SF-36: Short Form-36; TNFi: Tumour necrosis factor inhibitor; ULN: Upper limit of normal; VT: Vitality

\section{Acknowledgements \\ Under the direction of the authors, Katerina Kumpan, PhD, of Caudex, Oxford, UK (funded by Bristol-Myers Squibb), provided medical writing assistance for the development of this manuscript. Sandra Overfield, Protocol Manager, Bristol-Myers Squibb, assisted in initial design and operational aspects of the study.}

\section{Funding}

This study was funded by Bristol-Myers Squibb.

\section{Availability of data and materials}

Bristol-Myers Squibb's policy on data sharing may be found at https:// www.bms.com/researchers-and-partners/clinical-trials-and-research/ disclosure-commitment.html.

\section{Consent to participate}

All patients or their legal representatives gave written, informed consent prior to study entry. 


\section{Patient consent}

All patients or their legal representatives gave written, informed consent prior to study entry.

\section{Provenance and peer review}

Not commissioned; externally peer reviewed.

\section{Authors' contributions}

VS, PM and SB were responsible for the conception and design of the study, and the acquisition, analysis and interpretation of data. All authors had full access to the study data, critically reviewed the manuscript, approved the final version prior to submission, and take responsibility for the integrity and accuracy of the reported data.

\section{Ethics approval and consent to participate}

The study was conducted in accordance with the Declaration of Helsinki, International Conference on Harmonisation Guidelines for Good Clinical Practice and local regulations. Schulman Associates Institutional Review Board or Independent Ethics Committees approved the protocol, consent form and any other written information provided to patients or their legal representatives.

\section{Consent for publication}

Not applicable.

\section{Competing interests}

VS reports receiving consulting fees from AbbVie, Amgen Corporation, AstraZeneca, Biogen, Bristol-Myers Squibb, Boehringer Ingelheim, Celgene, Celltrion, Corrona, Crescendo/Myriad Genetics, EMD Serono, Genentech/ Roche, GlaxoSmithKline, Janssen, Lilly, Merck, Novartis, Pfizer, Regeneron, Samsung, Sandoz, Sanofi and UCB. EA, TL, AJ, SB and HAA are employees of Bristol-Myers Squibb and report holding stock in Bristol-Myers Squibb. PJM reports receiving consulting fees from AbbVie, Amgen, Bristol-Myers Squibb, Celgene, Corrona, Janssen, Lilly, Merck, Novartis, Pfizer, Sun, UCB and Zynerba; and speaker fees from AbbVie, Amgen, Bristol-Myers Squibb, Celgene, Genentech, Janssen, Novartis, Pfizer and UCB.

\section{Publisher's Note}

Springer Nature remains neutral with regard to jurisdictional claims in published maps and institutional affiliations.

\section{Author details}

'Division of Immunology/Rheumatology, Stanford University School of Medicine, Palo Alto, CA, USA. ${ }^{2}$ Bristol-Myers Squibb, Princeton, NJ, USA.

${ }^{3}$ Swedish Medical Center and University of Washington, Seattle, WA, USA.

\section{Received: 17 September 2018 Accepted: 14 November 2018} Published online: 06 December 2018

\section{References}

1. Gladman DD, Antoni C, Mease P, Clegg DO, Nash P. Psoriatic arthritis: epidemiology, clinical features, course, and outcome. Ann Rheum Dis. 2005; 64(Suppl 2):ii14-7.

2. Finlay AY, Khan GK. Dermatology Life Quality Index (DLQI)--a simple practical measure for routine clinical use. Clin Exp Dermatol. 1994;19(3):210-6.

3. Hewlett S, Dures E, Almeida C. Measures of fatigue: Bristol Rheumatoid Arthritis Fatigue Multi-Dimensional Questionnaire (BRAF MDQ), Bristol Rheumatoid Arthritis Fatigue Numerical Rating Scales (BRAF NRS) for severity, effect, and coping, Chalder Fatigue Questionnaire (CFQ), Checklist Individual Strength (CIS2OR and CIS8R), Fatigue Severity Scale (FSS), Functional Assessment Chronic IIIness Therapy (Fatigue) (FACIT-F), MultiDimensional Assessment of Fatigue (MAF), Multi-Dimensional Fatigue Inventory (MFI), Pediatric Quality Of Life (PedsQL) Multi-Dimensional Fatigue Scale, Profile of Fatigue (ProF), Short Form 36 Vitality Subscale (SF-36 VT), and Visual Analog Scales (VAS). Arthritis Care Res (Hoboken). 2011;63(Suppl 11):S263-S86.

4. Husted JA, Gladman DD, Long JA, Farewell VT. A modified version of the Health Assessment Questionnaire (HAQ) for psoriatic arthritis. Clin Exp Rheumatol. 1995;13(4):439-43.
5. Husted JA, Gladman DD, Farewell VT, Long JA, Cook RJ. Validating the SF-36 health survey questionnaire in patients with psoriatic arthritis. J Rheumatol. 1997;24(3):511-7.

6. Mease PJ. Measures of psoriatic arthritis: Tender and Swollen Joint Assessment, Psoriasis Area and Severity Index (PASI), Nail Psoriasis Severity Index (NAPSI), Modified Nail Psoriasis Severity Index (mNAPSI), Mander/ Newcastle Enthesitis Index (MEI), Leeds Enthesitis Index (LEI), Spondyloarthritis Research Consortium of Canada (SPARCC), Maastricht Ankylosing Spondylitis Enthesis Score (MASES), Leeds Dactylitis Index (LDI), Patient Global for Psoriatic Arthritis, Dermatology Life Quality Index (DLQI), Psoriatic Arthritis Quality of Life (PsAQOL), Functional Assessment of Chronic Illness Therapy-Fatigue (FACIT-F), Psoriatic Arthritis Response Criteria (PsARC), Psoriatic Arthritis Joint Activity Index (PsAJAl), Disease Activity in Psoriatic Arthritis (DAPSA), and Composite Psoriatic Disease Activity Index (CPDAI). Arthritis Care Res (Hoboken). 2011;63(Suppl 11):S64-85.

7. Bruce B, Fries JF. The Stanford Health Assessment Questionnaire: dimensions and practical applications. Health Qual Life Outcomes. 2003;1:20.

8. Cutolo M, Nadler S. Advances in CTLA-4-lg-mediated modulation of inflammatory cell and immune response activation in rheumatoid arthritis. Autoimmun Rev. 2013;12(7):758-67.

9. Orencia Prescribing Information 2017 February 2, 2018. Available from: http://packageinserts.bms.com/pi/pi_orencia.pdf. Accessed 2 Feb 2018.

10. Mease PJ, Gottlieb AB, van der Heijde D, FitzGerald O, Johnsen A, Nys M, et al. Efficacy and safety of abatacept, a T-cell modulator, in a randomised, double-blind, placebo-controlled, phase III study in psoriatic arthritis. Ann Rheum Dis. 2017;76:1550-8.

11. Gossec L, Smolen JS, Ramiro S, de Wit M, Cutolo M, Dougados M, et al. European League Against Rheumatism (EULAR) recommendations for the management of psoriatic arthritis with pharmacological therapies: 2015 update. Ann Rheum Dis. 2016;75(3):499-510.

12. Taylor W, Gladman D, Helliwell P, Marchesoni A, Mease P, Mielants $H$. Classification criteria for psoriatic arthritis: development of new criteria from a large international study. Arthritis Rheum. 2006;54(8):2665-73.

13. Gladman DD, Mease PJ, Cifaldi MA, Perdok RJ, Sasso E, Medich J. Adalimumab improves joint-related and skin-related functional impairment in patients with psoriatic arthritis: patient-reported outcomes of the Adalimumab Effectiveness in Psoriatic Arthritis Trial. Ann Rheum Dis. 2007;66(2):163-8.

14. Mease PJ, Woolley JM, Bitman B, Wang BC, Globe DR, Singh A. Minimally important difference of Health Assessment Questionnaire in psoriatic arthritis: relating thresholds of improvement in functional ability to patientrated importance and satisfaction. J Rheumatol. 2011;38(11):2461-5.

15. Kosinski M, Zhao SZ, Dedhiya S, Osterhaus JT, Ware JE Jr. Determining minimally important changes in generic and disease-specific health-related quality of life questionnaires in clinical trials of rheumatoid arthritis. Arthritis Rheum. 2000;43(7):1478-87.

16. Shikiar R, Willian MK, Okun MM, Thompson CS, Revicki DA. The validity and responsiveness of three quality of life measures in the assessment of psoriasis patients: results of a phase II study. Health Qual Life Outcomes. 2006;4(1):71.

17. Strand V, Mease P, Burmester GR, Nikaï E, Coteur G, van Vollenhoven R, et al. Rapid and sustained improvements in health-related quality of life, fatigue, and other patient-reported outcomes in rheumatoid arthritis patients treated with certolizumab pegol plus methotrexate over 1 year: results from the RAPID 1 randomized controlled trial. Arthritis Res Ther. 2009;11(6):R170.

18. Krishnan E, Sokka T, Häkkinen A, Hubert H, Hannonen P. Normative values for the Health Assessment Questionnaire disability index: benchmarking disability in the general population. Arthritis Rheum. 2004;50(3):953-60.

19. Strand V, Rentz AM, Cifaldi MA, Chen N, Roy S, Revicki D. Health-related quality of life outcomes of adalimumab for patients with early rheumatoid arthritis: results from a randomized multicenter study. J Rheumatol. 2012;39(1):63-72.

20. Revicki DA, Menter A, Feldman S, Kimel M, Harnam N, Willian MK. Adalimumab improves health-related quality of life in patients with moderate to severe plaque psoriasis compared with the United States general population norms: results from a randomized, controlled Phase III study. Health Qual Life Outcomes. 2008;6(1):75.

21. Webster K, Cella D, Yost K. The Functional Assessment of Chronic Illness Therapy (FACIT) Measurement System: properties, applications, and interpretation. Health Qual Life Outcomes. 2003;1:79.

22. Strand V, Boers M, Idzerda L, Kirwan JR, Kvien TK, Tugwell PS, et al. It's good to feel better but it's better to feel good and even better to feel good as soon as possible for as long as possible. Response criteria and the importance of change at OMERACT 10. J Rheumatol. 2011;38(8):1720-7. 
23. Mease $P$, van der Heijde $D$, Landewé $R$, et al. Secukinumab improves active psoriatic arthritis symptoms and inhibits radiographic progression: primary results from the randomised, double-blind, phase III FUTURE 5 study. Ann Rheum Dis. 2018;77:890-7.

24. Strand V, Sharp V, Koenig AS, Park G, Shi Y, Wang B, et al. Comparison of health-related quality of life in rheumatoid arthritis, psoriatic arthritis and psoriasis and effects of etanercept treatment. Ann Rheum Dis. 2012;71(7): $1143-50$.

25. Mease PJ, Woolley JM, Singh A, Tsuji W, Dunn M, Chiou CF. Patient-reported outcomes in a randomized trial of etanercept in psoriatic arthritis. J Rheumatol. 2010;37(6):1221-7.

26. Fleischmann R, Weinblatt ME, Schiff M, Khanna D, Maldonado MA, Nadkarni A, et al. Patient-reported outcomes from a two-year head-to-head comparison of subcutaneous abatacept versus adalimumab for rheumatoid arthritis. Arthritis Care Res (Hoboken). 2015;68(7):907-13.

27. Rahman P, Puig L, Gottlieb AB, Kavanaugh A, Mclnnes I, Ritchlin C, et al. SAT0264 ustekinumab improves physical function, quality of life and work productivity of patients with active psoriatic arthritis who were nalive to MTX, despite MTX therapy or previously treated with anti-TNF: results from Psummit I and Psummit II. Ann Rheum Dis. 2013;72(Suppl 3):A671-A2.

28. Ritchlin C, Rahman P, Kavanaugh A, Mclnnes IB, Puig L, Li S, et al. Efficacy and safety of the anti-IL-12/23 p40 monoclonal antibody, ustekinumab, in patients with active psoriatic arthritis despite conventional non-biological and biological anti-tumour necrosis factor therapy: 6-month and 1-year results of the phase 3 , multicentre, double-blind, placebo-controlled, randomised PSUMMIT 2 trial. Ann Rheum Dis. 2014:73(6):990-9.

29. Mclnnes IB, Mease PJ, Kirkham B, Kavanaugh A, Ritchlin CT, Rahman P, et al. Secukinumab, a human anti-interleukin-17A monoclonal antibody, in patients with psoriatic arthritis (FUTURE 2): a randomised, double-blind, placebo-controlled, phase 3 trial. Lancet. 2015;386(9999):1137-46.

30. Strand V, Mease P, Gossec L, Elkayam O, Van den Bosch F, Zuazo J, et al. Secukinumab improves patient-reported outcomes in subjects with active psoriatic arthritis: results from a randomised phase III trial (FUTURE 1). Ann Rheum Dis. 2017;76(1):203-7.

31. Kavanaugh A, Mease PJ, Gomez-Reino JJ, Adebajo AO, Wollenhaupt J, Gladman DD, et al. Treatment of psoriatic arthritis in a phase 3 randomised, placebo-controlled trial with apremilast, an oral phosphodiesterase 4 inhibitor. Ann Rheum Dis. 2014;73(6):1020-6.

32. Højgaard PKL, Orbai AM, Holmsted K, Bartels EM, Leung YY, Goel N, de Wit M, Gladman DD, Mease P, Dreyer L, Kristensen LE, FitzGerald O, Tillett W, Gossec L, Helliwell P, Strand V, Ogdie A, Terwee CB, Christensen R. A systematic review of measurement properties of patient reported outcome measures in psoriatic arthritis: A GRAPPA-OMERACT initiative. Semin Arthritis Rheum. 2018:47(5):654-65.

33. Mease $P$, Strand V, Gladman D. Functional impairment measurement in psoriatic arthritis: Importance and challenges. Semin Arthritis Rheum. 2018. https://doi.org/10.1016/j.semarthrit.2018.05.010.

34. Ware JE, Kosinski M. In: 2nd, editor. SF-36 Physical \& Mental Health Summary Scales: A Manual for Users of Version 1. Lincoln: QualityMetric Incorporated; 2001.

\section{Ready to submit your research? Choose BMC and benefit from:}

- fast, convenient online submission

- thorough peer review by experienced researchers in your field

- rapid publication on acceptance

- support for research data, including large and complex data types

- gold Open Access which fosters wider collaboration and increased citations

- maximum visibility for your research: over $100 \mathrm{M}$ website views per year

At $\mathrm{BMC}$, research is always in progress.

Learn more biomedcentral.com/submissions 